NASA Technical Memorandum 102887

\title{
The Aerospace Plane Design Challenge: Credible Computational Fluid Dynamics Results
}

Unmeel B. Mehta, Ames Research Center, Moffett Field, California

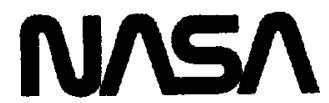

National Aeronautics and

Space Administration 



\title{
THE AEROSPACE PLANE DESIGN CHALLENGE: CREDIBLE COMPUTATIONAL FLUID DYNAMICS RESULTS
}

\author{
Unmeel B. Mehta \\ NASA Ames Research Center, Moffett Field, California
}

\begin{abstract}
Computational fluid dynamics (CFD) is necessary in the design processes of all current aerospace plane programs. Single-stage-to-orbit (SSTO) aerospace planes with air-breathing supersonic combustion are going to be largely designed by means of CFD. The challenge of the aerospace plane design is to provide credible CFD results to work from, to assess the risk associated with the use of those results, and to certify CFD codes that produce credible results. To establish the credibility of CFD results used in design, the following topics are discussed: CFD validation vis-à-vis "measurable" fluid dynamics (MFD) validation; responsibility for credibility; credibility requirement; and a guide for establishing credibility. Quantification of CFD uncertainties helps to assess success risk and safety risks, and the development of CFD as a design tool requires code certification. This challenge is managed by "designing" the designers to use CFD effectively, by ensuring quality control, and by balancing the design process. For designing the designers, the following topics are discussed: how CFD design technology is developed; the reasons Japanese companies, by and large, produce goods of higher quality than their U.S. counterparts; teamwork as a new way of doing business; and how ideas, quality, and teaming can be brought together. Quality control for reducing the loss imparted to the society begins with the quality of the CFD results used in the design process, and balancing the design process means using a judicious balance of CFD and MFD.
\end{abstract}

\section{Introduction}

During the 1980s aerospace plane programs were begun in every major technological nation. Unmanned and manned, and single-stage-to-orbit (SSTO) and two-stages-to-orbit (TSTO) designs are being pursued. SSTO designs are fully reusable, whereas TSTO designs may be either fully reusable or semi-reusable. Some of the aerospace plane programs call for building experimental planes, some for operational planes. Most of these programs are using largely state-of-the-art technologies (e. g. see Ref. 1). However, programs undertaken to design SSTO aerospace planes with supersonic combustion require critical new technologies, principally that of air-breathing propulsion over a wide range of Mach numbers. A significant and common factor among all aerospace plane programs is computational fluid dynamics (CFD), which is essential to the design process. (CFD is used herein to encompass 
a range of related areas, in which computations are done, such as aerodynamics, combustion, rarified gas dynamics, and aerothermodynamics.) The objective of this paper is to define the challenge that designing aerospace planes presents to the computational fluid dynamics community and to present a plan for addressing this challenge.

The design process for a new fluid dynamics system can begin only when there is at least some understanding of the flow field associated with that system. The requirements and technologies related to materials, structures, control systems, etc. are determined only after some information about the flow field is acquired. For example, it is the flow field that determines structural heat loads which in turn determine the characteristics of the materials required. If such materials are not available, then the necessary technology needs to be developed in order to produce them. Once the fluid dynamics design is developed, structural integrity becomes the primary concern. Until that integrity can be ensured, the design is reworked.

Flow-field knowledge is acquired through experimentation in ground-based test facilities and by theoretical methods; "measurable"2 technology and theoretical technology may have to be developed in order to acquire the flow-field information that is needed. Unlike aircraft such as the X-15, SR-71, and F-16, for which old-time slide rules and desk calculators provided most of the theoretical fluid-dynamics design input, the aerospace plane design will rely heavily on supercomputers.

In the 1970s the Space Shuttle was built largely with off-the-shelf technology. ${ }^{3}$ Two approaches were used in the design process: analysis and measurement. The analysis was based on simplifying assumptions about the governing equations, physics, and simple shapes. It was later determined that the ground-based testing and the design methods that were used did not do a good job of predicting the aerodynamic characteristics, which were actually determined only during the Space Shuttle flight program. ${ }^{4,5}$ For example, the orbiter experienced nose-up pitching moments, during entry at hypervelocities, that exceeded the established variations. ${ }^{6,7}$ Because the Shuttle was designed using tolerances (based on measurement scatters) and variations (from model to full-scale) in aerodynamic coefficients, it was possible to tolerate very large discrepancies in preflight aerodynamic data. ${ }^{5}$ The lessons learned from the Space Shuttle flight program suggest that improved design methods must be developed, even for designing aerospace planes that use largely state-of-the-art technologies. Such design methods would be based on improved ground-based measurements and on complex analyses involving the various forms of the Navier-Stokes and higher-order equations as well as actual vehicle shapes.

The existing data base for designing SSTO aerospace planes with supersonic combustion is very limited, and the existing ground-based test facilities and test techniques are deficient for developing an adequate data base. ${ }^{8-13}$ Currently planned new facilities and modifications of existing facilities will be a great help, but ground-based testing has its limitations. There are fundamental difficulties in creating complete flight simulations in ground-based facilities. Computational fluid dynamics, on the other hand, can go a long way toward filling the present void in the data base and complementing ground-based testing. Specifically, in major portions of the flight envelopes of these planes, CFD will be required to determine 
the performance and specifications of the fluid dynamics designs.

The challenge posed by all aerospace plane design efforts is to obtain credible CFD results, to assess the probable (quantified) uncertainties in those results, and to certify ${ }^{14}$ the codes as tools. The credibility of performance quantities is critical in the design process. The uncertainties lead to assessments of the success risk and safety risks associated with the fluid dynamics designs. The computer codes that generate credible results are certified by documenting their strengths and weaknesses, limitations, range of applicability and the manner of their use. Further, this challenge is managed by "designing the designers" 15 to properly use CFD, by instituting checks and balances in the process of generating CFD results, and by having a balance of computations and measurements. Fortunately, technical solutions for addressing this challenge are at hand.

\section{Credibility of CFD Results Used for Design}

The credibility of the CFD results is the responsibility of the users of those results. In the context of the aerospace plane, the users are the designers, the computational fluid dynamicists, and the measurable fluid dynamicists who are involved in the design process. They may either establish this credibility themselves or they may use appropriately certified codes. Just as credibility, or the lack of it, is a characteristic of computed results, reliability, or the lack of it, is a characteristic of codes. Certified codes are not available for the design of aerospace planes; the CFD design technology is yet to be developed (Fig. 1). Ultimately, the credibility of the design is determined by the credibility of the computed results used in the design process. Note that the use of certified codes does not necessarily establish the credibility of the design; a reliable code may be used improperly. Various aspects of the credibility issue as it regards CFD results for use in the design process as well as recommendations for establishing that credibility are discussed below.

\section{Computational and Measurable Fluid Dynamics Validation}

Some observations about the status of "CFD validation" and issues relevant to validation, calibration, and verification have been discussed previously. ${ }^{4,16}$ Recently, CFD validation was declared to be a process that never achieves its objectives. "In principle, validation is a continuous never ending process." 17 And, "The development process . . . presents a dilemma because code validation is actually an open-ended process brought about by the ever-widening scope and accelerated pace of possible applications compared with the ability to provide experimental validation and by algorithm enchancements that are progressively being introduced."18 Again, "Validation . . . is an ongoing process that parallels the development of CFD tools." 19 Such declarations may be appropriate in all types of research, except programmatic research, ${ }^{14}$ or may be used for obtaining carte blanche to work on code (or CFD) validation or to continually justify new test facilities and instrumentations. However, there has to be a periodical statement of the status of validation based on the state of the art of CFD for a class of flow problems. In this sense, validation is a time-constrained, closed-end process. Further, the focus when using CFD results in design should be on the level of their credibility, or on the quantified uncertainties, and on improving that credibility rather than on validation. 
Recently, the results of 38 computations from three codes were compared with measurements, or with the results of other computations, for the purpose of code calibration for configuration analysis. ${ }^{20}$ That comparison study is a good starting point for CFD calibration, but the bottom line is missing: the codes are not reported to have been calibrated. What can these codes predict accurately? What is the credibility of the computed results? What are the limitations of the computed results? When should these codes be used? How well can the performance quantities be predicted? Without providing answers to these kinds of questions, such comparisons are incomplete for application to the design process. Another example is a quite good status report of the validation efforts undertaken for two codes. ${ }^{21}$ It concludes with the following statement: "Excellent agreement [is] obtained between computations and experiment for a wide variety of test cases." But it, too, fails to answer the above questions. Specifically, "excellent" needs to be quantified for design applications.

In the aforementioned examples, it is not stated what code options, if any, were used when the results presented were generated. These options should be a part of the status report. If different options were used, then the various results generated with a code are not generated with the same code, even though the name of the code is the same. On the other hand, often a change is made in a code but not in its name. The details of the code are what matter, not its name.

Computational fluid dynamics validation is no different from measurable fluid dynamics (MFD) validation related to ground-based testing for simulating flight reality (Fig. 2). There are uncertainties in both computed results and in measurements. The CFD validation requires addressing uncertainties introduced by 1) a lack of equivalence between theoretical and computational models, 2) unsatisfactory computational accuracy, 3) isolation of phenomena, 4) extraneous phenomena, 5) improper modeling of phenomena, 6) creative overbelief, 7) definitions, 8) risk assessment, and 9) the decision-making process. The MFD validation requires addressing uncertainties introduced by 1) interference effects, 2) unsatisfactory measurement accuracy, 3) insufficiency of measurements, 4) isolation of phenomena, 5) extraneous phenomena, 6) creative overbelief, 7) definitions, 8) risk assessment, and 9) the decision-making process. Isolation of phenomena and extraneous phenomena include the uncertainty owing to scaling from ground-based tests to flight conditions. The crucial differences between CFD validation and MFD validation are modeling of phenomena and insufficiency of measurements. (A discussion of various uncertainties in CFD and MFD for hypersonic flight estimates is given in Ref. 16.) In spite of the limitations of the measurements, designers have been able to design aircraft that are now flying at subsonic, transonic, and supersonic speeds. The limitations of computed results must be determined and then those results must be appropriately applied to the design of aerospace planes that will fly at hypersonic speeds.

\section{Responsibility for Credibility}

Sometimes, results computed by the originating organizations are considered more credible than those generated by others. Because of "functional parochialism" those who conduct research usually do not produce results needed by the users. ("Functional parochialism" is a phrase attributed to Stephen Holmes by Cortes-Comerer. ${ }^{22}$ ) In fact, workers in industry 
are better suited for and have more incentive for and experience in design-like computations and design computations than do research institutions. Actually, computed results have to be evaluated irrespective of who generated them.

The design CFD codes may be developed from research codes. The purpose of research codes is to develop and validate numerical and physical modeling methods. Establishing the credibility of CFD research results does not necessarily establish the credibility of CFD design results. Research laboratories are responsible for developing the research codes and for the numerical and physical modeling concepts; however, they are not responsible for the credibility of computed results used in the design process. On the other hand, the computational fluid dynamicists involved in the design process are responsible for developing design codes. Users of CFD are principally responsible for using CFD appropriately and for ascertaining the credibility of computed results. The burden of proof lies with the users to show that the level of complexity used when the results were generated was such that further complexity would not change the conclusions drawn from the results. In addition to this issue of the level of complexity, the burden of proof also lies with the users and code developers to show that CFD uncertainties have been addressed and that the credibility of CFD results has been established, if the codes used have not been certified.

The primary responsibility of a CFD group in industry is to use CFD to support the design process by determining performance estimates and global flow fields that are accurate and affordable. To fulfill this responsibility, the CFD group has the following tasks: develop CFD design technology, participate in the design process, develop and enchance CFD tools, maintain quality control of CFD results, and determine probable uncertainties in the computed results. Thus, the CFD group is not only responsible for CFD methods, but for CFD design technology. Methods are a part of technology.

\section{Credibility Requirement}

The issue is not CFD validation or code validation or code calibration. The issue is what is the level of credibility of computed results or what are the quantified uncertainties associated with these results for designing the aerospace plane so that it will meet some specific operational goals. The designers associated with a program and oversight committees or committees external to this program are concerned with the credibility of computed results that lead to the design of a fluid-dynamics system. Recall that the Space Shuttle was designed with tolerances and variations. Likewise, the design and development of aerospace planes require margins that can be determined by quantifying uncertainties. ${ }^{14} \mathrm{~A}$ validated or calibrated code is not sufficient; such a code also has uncertainties. These uncertainties are needed in the design process. Considering that the modeling, for example, of turbulence is still not in hand after more than 50 years of serious effort, CFD validation, which has been in vogue since the mid $1970 \mathrm{~s}$, is an elusive goal for current aerospace plane programs. If CFD validation is defined as a process, ${ }^{17-19,21}$ then the outcome of that process is of doubtful use in a design application. What is of a paramount concern for the fluid-dynamics design is quantification of the CFD uncertainties and the management of those uncertainties so that their magnitude is appreciably reduced. 
The fluid-dynamics specifications of a fluid-dynamics system are essentially determined by the performance parameters and, to some extent, by the global flow fields. These parameters and flow fields are important in the design process. Therefore, their credibility must be determined. The CFD credibility requirement calls for the determination of the level of credibility or quantification of the uncertainties related to CFD-determined performance estimates and global flow fields. A related issue is computational fluid dynamics accuracy. The utility of CFD results determines the level of accuracy required of these results. In either case, the approach is a top-down one.

The philosophy of utilizing the top-down approach is new when applied to the use of CFD in the design process. Computational requirements for making hypersonic flight performance estimates to implement this philosophy have been discussed previously. ${ }^{14,23}$ Recently, Povinelli ${ }^{24}$ and Marvin ${ }^{25}$ for the first time discussed further applications of this philosophy. The performance estimates are required for making design evaluations, determining design sensitivities and optimization, establishing a design data base, and providing ground-based test support. The level of accuracy required is quantified by the degree to which specifications are sensitive to performance quantities and in turn the degree to which performance quantities are sensitive to computational errors. These sensitivities may change as a design evolves from the conceptual to the preliminary to the final phases. The need for ascertaining the required level of accuracy is dictated by the need for keeping the computational cost affordable.

The global flow fields are useful for understanding the physics and in making trade-off studies. The primary requirement for these flow fields is qualitative accuracy to a level determined by their utility. For example, such accuracy is sufficient for trade-off studies that seek to discern global trends. At times, quantitative accuracy is required when relative changes in some aspects of global flow fields are sought and when performance parameters depend on such global characteristics. An example of the latter is the accurate determination of the location of the bow shock wave at the inlet plane of an air-breathing aerospace plane so that the inlet performance parameters may be computed accurately. Either computational or fluid-dynamics uncertainties or both may exist. A shock-capturing numerical method without a solution-adaptive grid system may cause a problem in identifying the exact location of the shock wave. If the physics of flow in the nose region of the aerospace plane include nonequilibrium chemistry but if equilibrium chemistry is used for computing the flow field, there may be an uncertainty in the location of the bow shock wave at the inlet plane. Further, quantitative accuracy in the physics of interest is necessary for the modeling of that physics in simplified CFD. The sensitivity of the physics to modeling determines the level of accuracy required.

In order to determine trends or relative changes, modeled numerics and physics and CFD input parameters, except the trend-causing parameters, must be kept the same unless there is an appreciable change in the physics. Specifically, only one code, not a mixture of codes, should be used. The bias and precision of computation must be preserved consistently when trends and relative changes are being determined. The conclusions of such studies may be verified by another code. 
As an example, performance parameters and global flow-field requirements for the nozzle of an SSTO aerospace plane with supersonic combustion are considered. The performance parameters are thrust, moment, and heat loads. The global flow fields involve a combination of some of the following phenomena: turbulence, relaminarization, retransition, catalyticity, chemical kinetics, combustion, shock interactions, shear-layer mixing, separation, secondary flows, combustion-nozzle interactions, aerodynamic interactions, module-to-module interactions, unsteadiness, and three-dimensionality. Computations of performance parameters and global flow fields determine the requirements for CFD. The level of computational accuracy required in performance parameters is determined by the sensitivity of these parameters to the specifications for the aerospace plane, for example, the takeoff gross weight, such that the operational goals set for it are achieved. Further, these parameters are sensitive to physical models. Likewise, the utility of global flow fields determines what physical phenomena need to be captured and with what complexity. Again, the issue is sensitivity. Essential aspects of sensitivities with examples have been discussed previously. ${ }^{14,16,26,27}$

\section{A Guide for Establishing Credibility}

There are two approaches to establishing the credibility of CFD results: measurable and computational. Since CFD numerically simulates physical and chemical reality through modeling, a comparison of computed results and measurements should determine the level of the credibility of the computed results. Essentially, the computational approach does not utilize test measurements. In this case, the credibility of modeling, of input parameters, of equivalence, and of numerical accuracy is determined. A sensitivity-uncertainty analysis is used. Both of these approaches are equally important and both should be used. They are complementary.

The CFD design technology development for space planes is done as follows. First, a systematic determination of the numerical accuracy of performance quantities is carried out. Second, the computed physics/chemistry is determined to be qualitatively satisfactory. Third, a part of the physics/chemistry modeled is validated by measurements and the fluid-dynamics uncertainties are determined, limited to this physics/chemistry found in unit, benchmark, or design-like flow problems. Fourth, computations that are likely to be unreliable are identified, and a sensitivity-uncertainty analysis is performed. Fifth, the complete physics/chemistry that is modeled is evaluated and the CFD uncertainties are quantified, and, if the modeling is not satisfactory, it is improved with measurements in flight tests. Note that the CFD design technology for a class of aerospace planes can be considered developed and ready for use as a tool only after this fifth item is addressed, and this has to be done before the completion of a technology development program.

It is nearly universally observed by people who participated in research, development, and flight-test activities of past experimental programs that "their" program was ended prematurely. ${ }^{28}$ The research and technology development program for an experimental plane is over soon after the plane's flight-test program is completed. But as long as the program continues, the technology development must continue. One of the challenges of the $\mathrm{X}$ 30 flight-test program is considered to be "the validity of the predictions upon which the vehicle design will be based." ${ }^{29}$ Rather the challenge for successful development of NASP 
derivative planes is to gather sufficient data so that the CFD design technology can be further developed while the flight-test program is under way. This continued development will also provide preflight computations to assist in the safe expansion of the flight envelope. ${ }^{14,30}$

The present situation relating to SSTO planes with supersonic combustion is no different from that prevailing in the computation of nuclear clouds. In the latter, there is a lack of good measurements. Particularly, the initial conditions required to numerically simulate the events are not always complete, and the background turbulence level is not known. The current effort consists of a four-point attack: $:^{31}$ validation of first-principles sub-models against benchmark data; single-parameter sensitivity studies to determine important parameters; one-to-one comparisons of the entire model with a suite of nuclear test data; and variations around specified baseline simulations to determine the robustness of the simulations. This effort is essentially the "method-confident" approach previously ${ }^{14,16}$ proposed and discussed for hypersonic flight estimates leading to code certification and to the development of credibility in CFD results; it was outlined above for the development of CFD design technology.

Measurements in ground-based tests or flight tests can establish the credibility of computed results if the following conditions are met: ${ }^{14}$ 1) flow quantities at the boundaries of the computational domain are available; 2) a relevant and sufficient quantity of qualitative and quantitative data are taken; 3) a data-uncertainty analysis is carried out to determine the bias (fixed) and precision (random and variable but deterministic) of measurements; 4) in design-like test articles, relevant performance quantities are measured; and 5) an independent evaluation of the quality of data is done. An additional condition for ground-based tests measurements is that the same model is tested and the same types of data are collected in at least two different facilities. The details of conditions 1), 2), and 4) should be determined by computational fluid dynamicists and by measurable fluid dynamicists before the test articles are fabricated. They need to function as a team.

A code-validation task force has recommended a useful list of experiments to achieve CFD validation for the NASP. ${ }^{25}$ Some of the recommended experiments have not documented freestream conditions. Without knowing the free-stream conditions, meaningful computations cannot be done for establishing the credibility of computational results. If these conditions are not known, then either measurements or computations should be done to define them. Computations may also be done to verify stated conditions. Further, a major shortcoming of this list is that the credibility of the measurements of the recommended experiments is not evaluated. Unless measurement uncertainties are known, the uncertainties in the computed results cannot be determined with these measurements.

A statement of criteria for a successful experimental test and a detailed CFD prediction of how the test article is going to perform should be completed before the test. This helps to establish the credibility of computed results, to validate the technical understanding of a design, and to ensure the effectiveness of a test program. Pre-test computations also help to eliminate surprises during tests and to identify poor test-article designs before these articles are fabricated and tested.

If measurement uncertainties are acceptable, then the uncertainties in CFD results are the 
differences between measurements and CFD results. Of course, this definition of uncertainty requires that the computed results be accurate.

The CFD results are sensitive to numerical and physical modeling factors. The numerical factors are equivalence between theoretical and computational models and computational accuracy. The only way the former sensitivities (equivalence) can be determined is by comparing two computed results, one without equivalence and the other with equivalence. The latter sensitivity (computational accuracy) is determined by grid-refinement studies. In the case of air-breathing SSTO space planes, the propulsion performance parameters are sensitive to global conservation of conservative variables and to the entropy condition. On the other hand, the physical factor is the physical model, for example, the turbulence model and flow-field governing equations. When measurements are not available, it is sometimes possible to determine sensitivity by computing the result in question with different models. Further, the sensitivity of the results to the input parameters is a factor that may be either computational or physical. These parameters include the computational model parameters and specifications, such as grid spacing, turbulence model constants, and the boundary conditions. A practical uncertainty analysis method for determining the uncertainties of the input parameters is based on sensitivity analysis. ${ }^{32}$

One of the computational requirements for hypervelocity flight performance estimates is consistency in determination of these estimates. ${ }^{14}$ This condition requires that the designers, computational fluid dynamicists, and measurable fluid dynamicists use the same method for making these estimates. Differences in these estimates owing to differences in methods are not considered to be CFD uncertainties. Because of differences in the methods, different computational fluid dynamicists may get different estimates for the same computed flow field. Consistency in the method is obviously essential.

A comparison of the results of different, uncertified codes solving the same governing equations and the same physical problem does not necessarily establish confidence in any one of these codes. Contrary to the claim that "numerical errors can be effectively identified by solution-to-solution comparisons . . . . [resulting from] code-to-code comparisons," 18 these errors are unlikely to be so identified. All codes may produce similar or different results. And similar results may all be erroneous. On the other hand, it is not at all obvious from such comparisons which one of these sets of results is the correct one. Without knowing the magnitude of computational uncertainties, it is not possible to identify the best among the sets of results. In order to understand the variations between the different sets of results, these uncertainties need to be traced to their sources. These sources are the level of grid dependency $\left(y^{+}\right.$, conservation of conservative variables, etc.) and equivalence. The use of the computer codes should also be investigated. An improper use is not an error or uncertainty; it is a mistake. If there are no user mistakes in generating the results and if all similar sets of results have similar levels of uncertainties, then differences in these sets of results provide error bands owing to computational variations resulting from the use of different computational "wind tunnels," just as different ground-based facilities do by providing slightly different measurement values for the same conditions.

Both computational and measurable approaches for establishing the credibility of CFD 
results are used as follows. First, the computational approach is used to determine the computational uncertainties. Then the measurable approach is undertaken to determine the uncertainties resulting from physical modeling by comparing these results with measurements that incorporate known measurement uncertainties and for the same flow conditions. These measurements may be related to unit, benchmark, or design-like problems or to flight problems. If there are no measurements available for the flows of interest, fluid-dynamics uncertainties of the computed results are determined. These uncertainties are essential at least for the modeled flow physics that has not been validated in unit, benchmark, or design-like problems. Those models, which have been validated, should be shown to be applicable to the flows of interest. Further, there are sometimes uncertainties associated even with these validated models. Whether these uncertainties can be transferred over from those for unit, benchmark, or design-like problems to the problem of interest needs to be investigated. When measurements are not available and the computational uncertainties are determined but the fluid-dynamics uncertainties are hard to determine, then a subjective process of establishing the credibility is carried out by submitting the results to a team of experts for evaluation. Only measurements related to problems of interest, such as flight problems, allow modeling uncertainties to be determined directly. In this sense, the CFD design technology is ready to use as a tool only after the flight measurements are used for establishing its credibility.

At the beginning of a program, the available numerics and physics are evaluated based on the likelihood of program requirements. Considering accuracy and ifordability during the life of the program, the top two types of numerics and physics are chosen for each application. A CFD consistency is sought in patching solutions across different applications or computational zones. These numerics and physics are coded in computer codes such that changes and additions related to them are relatively easy to incorporate. The availability of computer systems should also be considered. There should be one primary code and one backup code for each application, both of which are put through a certification process. During the course of the program, the numerics and physics may change. When that happens, a part of the process of certification or the entire process is repeated. However, at major milestones in the program the status of this process in terms of current levels of CFD uncertainties should be available to the designers. By the end of the program, there are

CFD tools available that can be used by designers in subsequent programs dealing with the same class of aerospace planes. These tools may require some modifications based on latest knowledge, but there is no need to develop all new tools. The procedures for modifying and developing additional tools would have been essentially established for the next program.

\section{Success Risk Assessment}

The primary requirements of CFD are 1) that the physics/chemistry of the boundary layer, mixing, and combustion are adequately modeled, and 2) that the necessary computing resources are available. The inability to fulfill these requirements leads to uncertainties in CFD results, which in turn lead to risk. Risk is never eliminated. The pertinent questions about risk are as follows: What is the magnitude of the risk? How much risk is acceptable? How should risk be managed? For establishing the level of credibility of CFD results, the first question is addressed in this section and the third is, partially, addressed here and elsewhere 
in this paper. The acceptance of risk depends on the quality of risk assessment methods, the rigor with which risk abatement is carried out, and rationally formulated criteria of acceptance. In addition to these technical considerations, the acceptable level of risk may be influenced by social or political judgments.

Risk analysts define risk as a combination of the probability of the occurrence of an undesirable event and each and every foreseeable consequence of that event. ${ }^{33}$ The System Engineering Management Guide defines risk as the uncertainty in attaining a standard. ${ }^{34}$ The National Aeronautics and Space Administration (NASA) has used the following definition: "The chance (qualitative) of loss of personnel capability, loss of system, or damage to or loss of equipment or property."35

It is suggested that there are two types of risk associated with aerospace planes: success risk and safety risk. Success risk is important during the conceptual and preliminary design phases; safety risk is a major concern during the final design phase and during the subsequent phases of an aerospace plane program. Success risk is the probability of not achieving the objectives of the program. Safety risks are the probability of potential failures and hazards associated with the space plane. Risk can be evaluated subjectively (qualitatively or psychologically) or objectively (quantitatively or logically). The Delphi technique of sampling experts is a subjective evaluation of risk. ${ }^{34}$ This evaluation determines a degree of belief that events or effects will occur. Such an evaluation is appropriate during the conceptual design phase. A qualitative evaluation of risk may be feasible only after there is an experience of quantitative evaluations. On the other hand, a probabilistic risk assessment logically utilizes available evidence to quantify risk. Quantitative risk assessment is necessary during the preliminary design phase and during subsequent phases of the program.

Quantitative risk assessment is required for credibility, success, margin, safety, reliability, and quality control. Addressing risk is addressing uncertainties. The credibility level of CFD results is determined by quantifying CFD uncertainties. A margin to be built into a design requires quantification of uncertainties, because the margin is a quantitative entity. The process through which the level of CFD credibility is established requires that: 1) the sensitivity of a design performance quantity (e.g., nozzle gross thrust coefficient) or specification (e.g., takeoff gross weight) of interest to numerical and physical parameters be identified; 2) the CFD uncertainties owing to these sensitivity parameters be quantified; and 3 ) the overall uncertainty in the chosen performance quantity or specification based on a collection of sensitivity parameters be determined. Once the overall CFD uncertainty is determined, the success risk or the margin required may be determined. In some cases, uncertainties in more than one performance quantity may be required; for example, in an air-breathing SSTO space plane the specific impulse depends on inlet efficiency, combustion efficiency, and nozzle thrust coefficient.

Two very useful and recent studies are reported in Refs. 36 and 37 . Reference 36 illustrates quantification of CFD uncertainties essentially as suggested previously ${ }^{16}$, and Ref. 37 demonstrates the determination of margin, given uncertainties in performance quantities and in a specification. Finley has presented a statistical technique for quantifying the credibility level in CFD drag predictions and determined the effect of this credibility on the vehicle fuel 
fraction required to achieve orbit. ${ }^{36}$ Cribbs has utilized a Monte Carlo procedure to compute the probability distribution of the maximum velocity of hypervelocity designs to determine the probability of success as a function of velocity. ${ }^{37}$

If the success risk is not acceptable, the design is changed. On the other hand, this risk is reduced, in part, by reducing the CFD uncertainties. The aforementioned risk assessment process identifies the uncertainties that are significant, thereby pointing the way to effective risk management. Since performance quantities are integrated quantities, this process also identifies details of the overall flow field that must be improved.

Those working on manned aerospace plane programs should be cognizant of the lessons learned regarding risk assessment and management from the Space Shuttle Challenger accident, from the human and organizational failures that led to that accident, and from the redesign of the Space Shuttle solid rocket booster. ${ }^{35,38-41}$ In order to assess risks, these programs need to consider the probabilistic risk assessment procedures such as those developed for nuclear power plants ${ }^{42}$ and that discussed by Gregory. ${ }^{26,27}$

\section{Code Certification}

The development of a tool from a technology requires the identification of the strengths, weaknesses, limitations, and range of applicability of the technology. A product of the CFD design technology development triad (Fig. 1) is design CFD cociss. To use a code as a tool, the user must know the characteristics of the code and how to apply it. The process of establishing the reliability and limits of applicability of the code is called code certification, ${ }^{23}$ and it is defined as follows: "The process of evaluating a computer code in terms of its logic, numerics, physics/chemistry, and the results, to ensure compliance with specific requirements." 14 A few aspects of this process are presented below, preceded by some background information about software "validation and verification" (V\&V) in the defense and nuclear industries.

Since the advent of the computer, the development of reliable software (computer codes) that can perform its intended function has been a challenge. Because of this challenge, for example, between 1975 and 1989 , at least 18 software studies were initiated in the United States by the Air Force, Department of Defense, and General Accounting Office. ${ }^{43}$ The motivation of these agencies in addressing this challenge is explained by the fact that in fiscal 1990, software development and maintenance accounted for about $10 \%$ of the defense budget. ${ }^{44}$

The reliability of software is seriously determined in at least two industries, defense and nuclear, because of the criticality of performance and system safety. There are about 250 Department of the Defense standards and policies that specify how software should be developed and acquired. ${ }^{44}$ Because of the problems associated with existing software practices, a master plan was recently prepared to address software acquisition, life-cycle management, policies, standards, personnel, and technology. The V\&V procedures initiated by the Defense Department for software controlling the operation of weapon systems have been the starting point for the V\&V guidelines for software used in nuclear power plants. The 
American Nuclear Society and the American Society of Mechanical engineers have prepared, respectively, guidelines for V\&V of scientific and engineering computer codes for the nuclear industry ${ }^{45}$ and quality assurance requirements for computer software for nuclear facility applications. ${ }^{46}$

The development of a software is usually done by a process referred to as a "waterfall model" or "software life-cycle phases." Generally, the model passes through the following stages: requirements, preliminary design, detailed design, coding, integration and testing, installation and checkout, operation and maintenance, and retirement. The development is categorized either as precedented or unprecedented, the main difference between these two categories being the level of understanding of the requirements.

The current development of computer codes for the CFD design process for aerospace planes falls into the unprecedented category (Fig. 1). At the completion of technology development aerospace programs, the development of computer programs for the follow-on programs would be categorized as precedented developments.

The defense and nuclear industries develop software for specific requirements and undertake the $V \& V$ process, which has a beginning and an end. But research institutes often develop CFD codes to have "the ever-widening scope and accelerated pace of possible applications." 18 The futility of developing a code for a "wide range of applications" (Fig. 1 of Ref. 18) has been discussed previously; ${ }^{14}$ The numerical and physical models, such as numerical models satisfying the second law of thermodynamics and turbulence models, need to be developed and validated for possible wide applications, not codes. Codes are developed for specific applications, both for model validation by the research institutes and for design application by the industry. These codes must be certified; that is, these codes must go through a process that would assure or inform with certainty to whom it may concern that they generate reliable results.

Unless the computational uncertainties are first determined and unless the fluid-dynamics modeling uncertainties are then quantified, a model cannot be validated. Unless the computational and fluid-dynamics uncertainties are quantified, design application cannot be credible. After uncertainties have been systematically documented and guidelines for using the code have been developed, the code can be a reliable tool. Code certification leads to the quantification of uncertainties and to the documentation of its utility for a specific application with specific requirements. Code certification also helps to qualify the user of the code.

The idea of code certification has been supported by Roache. ${ }^{47} \mathrm{He}$ has suggested that professional societies may become involved in the task of certification of commercially available CFD codes. However, CFD aerospace design applications and the codes developed for these applications would most likely be proprietary in nature rather than commercially available. How are these proprietary codes certified? To inform with certainty the people who need to know, the code-originating company itself has to collect and demonstrate the evidence in a handbook of code certification. Such handbooks should also be prepared for commercially available codes. The code-certification handbooks store corporate CFD knowledge. Doc- 
umentation to provide traceability is very important in code certification. The guidelines that may be used for code certification would, in principle, be the same as those for V\&V developed by the American Nuclear Society. ${ }^{45}$

\section{Designing the Designers for Using CFD}

Computational fluid dynamics may be used in the design process to achieve the following objectives: understanding the physics, making trade-off studies, determining design sensitivities and optimization, making design evaluations, developing the design data base, and supporting ground-based tests. "Aeropropulsion dynamics" designers, structural designers, and measurable fluid dynamicists, as well as computational fluid dynamicists use CFD in this design process. With CFD they can often address problems for which no design experience, data base, or test techniques exist. These kinds of problems exist, for example, in aeropropulsion dynamics, which includes aerodynamics, heat transfer, aerothermodynamics, propulsion, and airframe-propulsion integration. In working on an SSTO aerospace plane with supersonic combustion, the propulsion flow-path designer has to begin his design at the nose of the plane along the lower surface of the forebody, proceed through the inlet, combustor, and internal nozzle, then along the external nozzle, and, finally, complete his design at the end of the plane. The designers need to be "designed," as it were, to properly use CFD if they are to produce good designs.

\section{CFD Design Technology}

Computational fluid dynamics technology for application to aerospace plane designs is being developed. When its strengths, weaknesses, range of applicability, and limitations are known, it will become a useful design tool. A designer is effective only if he knows these characteristics of his design tools. Of course, some problems cannot be fixed with tools; knowledge and experience are also required. Given the same CFD code and the same flow conditions, two designers may compute two different sets of results if they are not trained in the proper use of the code.

The CFD design technology is developed during the design phase and during the flighttest program (Fig. 1). During the design phase, the computational fluid dynamicist collaborates with the designer and with the measurable fluid dynamicist who is conducting the ground-based tests. During the flight-test program, the computational fluid dynamicist further develops the CFD design technology by again collaborating with the measurable fluid dynamicist who is conducting the flight tests and by assisting in the flight-envelope expansion process.

To quickly learn how to use CFD, the designer has to team up with the computational fluid dynamicist. This is essential, and will continue to be, until the characteristics of CFD are well known for a given class of design problems. The computational fluid dynamicist cannot develop CFD technology without knowing and experiencing how this technology is going to be used; he and its user must work together to ensure its rapid development. Nevertheless, the computational fluid dynamicist is responsible for developing the CFD technology and for ensuring its proper use. The advantages of teaming up the computational fluid dy- 
namicist and the designer and establishing quality control of CFD results used in design are suggested based on the practices in Japanese companies.

\section{U.S. Companies versus Japanese Companies}

Concerning U.S. and Japanese companies, the following observations can be made. Although the United States is substantially ahead of Japan in basic research and has the lead (slim though it may be) in applied research, with some exceptions Japan leads in the production of high-quality goods. ${ }^{48}$ The U.S. companies generally have an edge in innovation, whereas the Japanese companies are usually more successful in incorporating innovations into quality products. There are at least three significant reasons for the Japanese successes. First, in the United States ideas are generally moved from one level or organization to another; in Japan, it is the people with the ideas who are usually moved from one organizational level to another. ${ }^{15}$ Second, in the United States, the quality of a product has been generally controlled during manufacturing, by manufacturing process controls, and only recently and to a limited extent during product and process design; in Japan, the quality of a product is primarily controlled during the design process by designing both product and process for quality. Third, in the United States, precompetitive teamwork between companies is only just beginning to take place; in Japan, such teamwork has existed for many years.

\section{Teamwork}

In the United States, teamwork is of growing importance in many industries because it cuts lead time, improves quality, and, therefore, cuts costs. For example, the Ford Motor Company discarded the traditional "over-the-transom" process of product design for planning the Taurus automobile and introduced a program team approach. ${ }^{22}$ This approach brings all resources together and blurs the distinction between research and development and manufacturing, beginning at the start of a design and development program. In the over-the-transom process there is usually a "caste" system and a "culture" to resist change. People are often entrenched in their work and priorities. Supervisors are unlikely to reward contributions to the overall organizational objectives that are outside their domain of responsibility. Thus, supervisors can put workers in catch-22 situations and discourage such efforts. Teamwork is hampered by the enforcement of organizational boundaries or by functional parochialism. In the team approach, people with the right cross-functional experience and attitude are required to form a multifunctional task force.

Teamwork is also taking place between nations and between competing companies. Partners benefit from each other's success, and results are often achieved that are better than those that could be achieved by either partner alone. An example is the National Aero-Space Plane (NASP) program for developing a precompetitive SSTO technology that incorporates supersonic combustion.

The formation of the National Contractor Team for the NASP program is most advantageous for both the U.S. government and contractors and ensures the broadest possible U.S. base in hypersonic technology. The NASP program examplifies a new mode of operation that is a strategic partnership between the government and industry. Teamwork between the six members of this program, five industrial members and the government (consisting 
of several government organizations), focuses on the best ideas and makes possible a more effective utilization of resources. The government member is a direct participant in the program work, and there is a totally open working relationship between the government and industry. An effective teaming at the program level requires effective teaming between the industrial members and between the government organizations.

To obtain the aforementioned benefits of teamwork there has to be give-and-take between people of diverse backgrounds and expertise. Just as in any organization, teamwork arrangements require safeguards against flawed decision-making processes that can result from the "group-think" 49 and the "Abilene" paradox ${ }^{50}$ phenomena. Group-think is a mode of thinking of a cohesive in-group whose members strive for unanimity rather than realistically appraised alternative courses of action. This phenomenon has three main symptoms: overestimation of group power and morality, close mindedness, and pressure to move toward uniformity. An apparent example is that "the sheer number of [Space Transportation System] related boards and panels seems to produce a mindset of 'collective responsibility.' "35 The Abilene paradox describes the tendency for organizations or groups to make decisions that may run contrary to the information they have about their problems, thus compounding the problems rather than solving them. For example, members of a group are often inclined to subordinate their own true feelings about a problem to what they perceive as a "group" preference. The inability to manage agreement is the primary symptom of this paradox. The decision to launch Challenger was an example. ${ }^{51}$ To confront this paradox from within an organization is quite difficult and is often done at a personal price. ${ }^{50,51}$ These two decision-making situations are avoided essentially by establishing checks and balances, having each member of the team function as a critical decision maker, seeking independent evaluations, allowing team members to play the role of devil's advocate, and providing a work environment that allows bad news to travel up through the organization.

\section{Ideas, Quality and Teaming}

The aforementioned advantages of transferring the people who have the ideas rather than just the ideas, designing for quality, and using teamwork suggest that designers need to work closely with computational fluid dynamicists to master the art of using CFD in the design process and to develop CFD design technology for applications in the design of aerospace planes. Computational fluid dynamicists can be used solely as consultants by designers only after the CFD design technology becomes a tool. The former have to be a part of the design process in order to make this technology a useful design tool, because a technology can be properly developed only when first-hand experience is gained in its intended application. The experience and knowledge of the computational fluid dynamicists make them responsible for the credibility and appropriateness of the computed results. They provide checks and balances and independent verification. The Total Quality Management System philosophy, which requires credible CFD results, their continuous improvement, and their affordability, is possible through the teamwork of designers and computational fluid dynamicists.

The best approach for developing the CFD design technology for the designers is a combination of design, measurements (ground-based and flight), and computations. This approach is the CFD design technology development triad illustrated in Fig. 1. With 
teamwork as its motto, a programmatic research ${ }^{14}$ and technology development program such as the NASP program is required for developing CFD design technology for aerospace planes and for designing the designers to use this technology.

\section{Quality Control}

The American Society for Quality Control defines quality as "the totality of features and characteristics of a product or a service that bear on its ability to satisfy [a user's] given needs." ${ }^{22}$ A better definition is given by Taguchi who said that quality is measured by "the loss imparted to the society from the time a product is shipped." 53 According to this definition, the function of quality control is to discover and implement techniques that produce net savings to society. The final quality and cost of a manufactured product are determined to a large extent by the engineering designs of the product, the designs of the processes for its manufacture, and its manufacturing process itself. Designing for quality results in better quality than do attempts to control quality only in process design and during manufacture. Quality control begins with the tools and technology used for design and continues through all subsequent steps. Thus, quality control includes how CFD is used in the design process.

Who is responsible for the quality control of the CFD results used in the design? The answer is that all who use CFD in the design process are responsible. Primarily, of course, the responsibility lies with the computational fluid dynamicist. He has to determine and provide guidelines for the level of CFD complexity and the level of computational accuracy required for all CFD design applications; moreover, he has to monitor the process to ensure that these guidelines are followed. Whether the guidelines have been met should not be determined after the CFD results are used in the design, because such after-the-fact evaluation causes a societal loss (in Taguchi's terms). If it is not possible to meet the guidelines, these results are flagged as deficient. Further, the guidelines help maintain uniformity and consistency in the use of CFD among the designers.

The configuration and component design teams are generally concerned with the design rather than with the details of how they get CFD results. The computational fluid dynamicist needs to know how CFD technology and tools are used in design; what are the strengths, weaknesses, and limitations of the applicability of CFD; what are the problems in applying CFD; and whether there are disconnects between him and the various design teams and between the design teams themselves. He gets these kinds of information by teaming up with the designer and by being involved in the design process. This information helps to improve CFD quality and, consequently, that of the design.

It is a common practice to have an independent validation and verification of software. Although it is required that this "checks and balances" practice be conducted by an organization independent of the program management structure and the organizations involved in the program, it still assists in quality control when instituted within a program. One of the team members is tasked to carry out 1) spot-validation of the numerics and physical modeling suggested by other members or organizations, 2) quantitative spot-verification of computed results used in design by other team members, and 3) spot-verification of trends 
and relative changes determined by other team members. The first of these three tasks is necessary for understanding and building confidence in the numerics and physics developed by others. The latter two help establish the credibility of computed results.

When the CFD design data base is developed, the principles of designing with quality or robust design based on the Taguchi's method ${ }^{54}$ helps to determine what data base should be generated. In the traditional method of studying the effect of a large number of factors, their effects have been studied one at a time. Obviously, this is a costly approach. Grouping factors into columns that form a matrix called an "orthogonal array" 54 provides an efficient method of developing this data base. With the orthogonal array method many factors are studied simultaneously.

\section{A Balanced Design Process}

A system design is optimized by trading off the performance and specifications of different parts to achieve a balance. One of four principles may be used for balancing the design: equal performance, equal cost, equal safety, or equal effectiveness. The first two principles are widely used; the third is essential, for example, for manned space activities, nuclear power generation, and chemical processes. The fourth ${ }^{55}$ is a geometric means of resource allocations as suggested by the first two principles. A balanced design process is achieved when the tools and technology used for the design are based on one of the following principles: equal credibility, equal cost, or equal effectiveness. The design of the SSTO aerospace plane with supersonic combustion requires CFD for about $70 \%$ of its flight envelope. The resources allocated to CFD should be commensurate with the responsibility placed on it. Based on the principles of a balanced design process, the allocated computational cost of CFD should be at least the same as that of ground-based tests. Both CFD and MFD consist of tools and technologies.

Historically, ground-based testing alone has not proved adequate for design purposes. ${ }^{10}$ Design problems associated with hypervelocity flight can be addressed properly only when ground-test data, flight-test data, and computations for a given class of aerospace planes are used together.

The development of an operational aircraft or spacecraft is traditionally done with work breakdown structures related to the operational aspects as primary line items. Although this development policy is also applicable to the development of an operational aerospace plane, there should be equal emphasis on operations and technology in the development of an experimental (research and technology development) aerospace plane, during the conceptual and preliminary design phases. At the end of the preliminary design phase, the decision to proceed further on to final design, construction, and flight-test program is primarily contingent on the status of the technology rather than on the status of operations, when the latter is difficult to establish without a flight test. Further, the usual practice is to identify ground-based tests and flight tests as line items. But computations are no less important than the tests.

The management of operational requirements and technology development requirements 
is better done by a matrix organization rather than by two separate organizations. In particular, a three-dimensional matrix organization is required for developing the CFD design technology, with the design group on one side, the CFD group on the other, and the groundbased and flight-test group on the third side of the matrix.

\section{Concluding Remarks}

Computational fluid dynamics is an essential part of the design process for aerospace planes. The challenge posed by these design efforts is to obtain credible CFD results for reducing success risk and safety risks and for certifying computer codes to be used as tools. This challenge is addressed by determining the level of credibility or the probable uncertainties in computed results, by improving this credibility, by risk assessment, and by code certification. The credibility of a design is no better than the credibility of the technologies and tools used in its development. Addressing the uncertainties is addressing risks. It is recommended that success risk in the preliminary design phase and safety risks in the final design phase and subsequent phases of an aerospace plane program be evaluated quantitatively. The challenge is managed by developing and applying the CFD design technology. This development and application is achieved by teaming the designers, computational fluid dynamicists, and measurable fluid dynamicists, by controlling the quality of computed results, and by balancing the design process. The aerospace plane design challenge of working from credible computational fluid dynamics results can be met.

Specifically, the following conclusions are noted:

1) In the design of aerospace planes, CFD is as important as MFD. Because of the limitations of current ground-based facilities, in about the upper $70 \%$ of the flight envelopes of SSTO aerospace planes with supersonic combustion, CFD will be required to determine fluid-dynamics performance and specifications.

2) What is of a paramount concern for fluid dynamics design is not CFD code validation but quantification of CFD uncertainties so that their magnitude is appreciably reduced and so that these uncertainties are used for designing with margin.

3) Quantitative (probabilistic) risk assessment is required for credibility, success, margin, safety, and quality control.

4) Model validation is a principal responsibility of research institutes, and CFD design application is a principal responsibility of industry. Both activities are carried out with CFD codes that must go through a process to inform with certainty (to certify) the reliability of the results produced by them.

5) The designers need to be "designed" to properly use CFD if they are to produce good designs.

6) The Total Quality Management System philosophy requires quality control of CFD that is used in the design process.

7) The principles of balancing the design process need to be used to determine the cost of computations vis-à-vis ground-based tests. 


\section{References}

${ }^{1}$ Ashford, D. M. and Collins, P. Q., "The Prospects for European Aerospace Transporters, Parts I-IV," Aeronautical Journal, Jan.-Mar. 1989.

${ }^{2}$ Gregory, T. J., Private Communication, NASA Ames Research Center, Moffett Field, Calif., Oct. 1990.

${ }^{3}$ Space Technology to Meet Future Needs, Committee on Advanced Space Technology, Aeronautics and Space Engineering Board, National Research Council, National Academy Press, Washington, D.C., 1987.

${ }^{4}$ Hamilton, J. T., Wallace R. O., and Dill, C. C., "Launch Vehicle Aerodynamic Data Base Development Comparison with Flight Data," Shuttle Performance: Lessons Learned, NASA CP-2283, Part 1, 1983.

5Silveria, M. A., "The Beginning of a New Aerodynamic Research Program," Shuttle Performance: Lessons Learned, NASA CP 2283, Part 2, 1983.

${ }^{6}$ Woods, W. C., Arrington, J. P., Hamilton, H. H., II, “A Review of Preflight Estimates of Real-Gas Effects on Space Shuttle Aerodynamic Characteristics," Shuttle Performance: Lessons Learned, NASA CP-2283, Part 1, 1983.

${ }^{7}$ Griffith, B. J., Maus, J. R., and Best, J. T., "Explanation of the Hypersonic Longitudinal Stability Problem - Lessons Learned," Shuttle Performance: Lessons Learned, NASA CP. 2283, Part 1, 1983.

${ }^{8}$ Review of Aeronautical Wind Tunnel Facilities, Committee on Assecsment of National Aeronautical Wind Tunnel Facilities, Aeronautical and Space Engineering Board, National research Council, National Academy Press, Washington, D.C., 1988.

${ }^{9}$ Hypersonic Technology for Military Application, Committee on Hypersonic Technology for Military Application, Air Force Studies Board, National Research Council, National Academy Press, Washington, D.C., 1989.

${ }^{10}$ Requirements for Hypersonic Test Facilities, Report of the Ad Hoc Committee, United States Air Force Scientific Advisory Board, Department of the Air Force, Washington, D.C., May 1989.

${ }^{11}$ Harsha, P. and Waldman, B., "The NASP Challenge: Testing for Validation," AIAA Paper 89-5005, Dayton, Ohio, 1989.

${ }^{12}$ Hornung, H. G. and Belanger J., "Role and Techniques of Ground Testing for Simulation of Flows up to Orbital Speed," AIAA Paper 90-1377, Seattle, Wash., 1990.

${ }^{13}$ Neumann, R. D., "Requirements in the 1990's for High Enthalpy, Ground Test Facilities for CFD Validation," AIAA Paper 90-1401, Seattle, Wash., 1990.

${ }^{14}$ Mehta, U. B., "Computational Requirements for Hypersonic Flight Performance Estimation," Invited AIAA Paper 89-1670, Buffalo, N.Y., 1989; also Journal of Spacecraft and Rockets, Vol. 27, No. 2, Mar.-Apr., 1990.

${ }^{15}$ Westney, E. and Sakakibara, K., "Designing the Designers, Computer R\&D in the United States and Japan," Technology Review, Apr. 1986.

${ }^{16}$ Mehta, U. B., "Some Aspects of Uncertainty in Computing Hypersonic Flight Estimates," an invited presentation at the Forum on Methods for Estimating Uncertainty Limits in Fluid Flow Computations, ASME Winter Annual Meeting, San Francisco, Calif., Dec. 1989; also NASA TM-102804, 1990. (Submitted to the ASME Journal of Fluids Engineering.) 
${ }^{17}$ Martellucci, A., "The Challenging Process of Validating CFD Codes," AIAA Paper 90-1402, Seattle, Wash., 1990.

${ }^{18}$ Marvin, J. G. and Holst, T. L., "CFD Validation for Aerodynamic Flows: Challenge for the 90's," AIAA Paper 90-2995, Portland, Oreg., 1990.

${ }^{19}$ Neumann, R. D., "CFD Validation - The Interaction of Experimental Capabilities and Numerical Computations," AIAA Paper 90-3030, Portland, Oreg., 1990.

${ }^{20}$ Green, M. J., "Code Calibration for Configuration Analysis," Proceedings of the 7th National Aero-Space Plane Technology Symposium, Vol. II, NASP CP-7041, NASA Lewis Research Center, Cleveland, Ohio, Oct. 1989.

${ }^{21}$ Rudy, D. H., "Summary of Validation Efforts for CFL3D and SPARK Codes," Proceedings of the 8th National Aero-Space Plane Technology Symposium, Vol. II, NASP CP-8047, Naval Postgraduate School, Monterey, Calif., 1990.

${ }^{22}$ Cortes-Comerer, N., "Motto for Specialists: Give Some, Get Some," IEEE Spectrum, May 1987.

${ }^{23}$ Mehta, U. B., "Flight Performance Estimation Utilizing Computational Fluid Dynamics," Proceedings of the 5th National Aero-Space Plane Technology Symposium, Vol. I, NASP CP-5028, NASA Langley Research Center, Hampton, Va., Oct. 1988.

${ }^{24}$ Povinelli, L. A., "Advanced Computational Techniques for Hypersonic Propulsion," 9th International Symposium on Air Breathing Engines, Athens, Greece, Sept. 1989; also NASA TM-102005, 1989.

${ }^{25}$ Marvin, J. G., "CFD Validation for NASP," Proceedings of the 7th National AeroSpace Plane Technology Symposium, Vol. II, NASP CP-7041, NASA Lewis Research Center, Cleveland, Ohio, Oct. 1989.

${ }^{26}$ Gregory, T. J., "National Aero-Space Plane Design Fundamentals and Evaluation," AIAA Paper 88-4504, Sept. 1988.

${ }^{27}$ Gregory, T. J., "Credibility of NASP," Aerospace America, Sept. 1989.

${ }^{28}$ Gulcher, R., "The Past as Prologue," AIAA Paper 89-5004, Dayton, Ohio, 1989.

${ }^{29}$ Wierzbanowski, T., "The Challenge of X-30 Flight Test," AIA A Paper 89-5015, Dayton, Ohio, 1989.

${ }^{30}$ Mehta, U., "The Role of Computational Fluid Dynamics," Summary of Workshop on Supersonic Combustion, NASP Workshop Publication 1003, June 1988.

${ }^{31}$ Bacon, D. Private Communication, Science Applications International Corporation, McLean, Va., Aug. 1990.

${ }^{32}$ Ronen, Y., ed., Uncertainty Analysis, CRC Press, Inc., Boca Raton, Fla., 1988.

${ }^{33}$ Bell, T. E., "Managing Murphy's Law: Engineering a Minimum-Risk System," IEEE Spectrum, June 1989.

${ }^{34}$ System Engineering, Management Guide, Defense Systems Management College, Fort Belvoir, Va., Oct. 1983, (N84-19129).

${ }^{35}$ Post-Challenger Evaluation of Space Shuttle Risk Assessment and Management, Committee on Shuttle Criticality Review and Hazard Analysis Audit, Aeronautics and Space Engineering Board, National Research Council, National Academy Press, Washington, D.C., Jan. 1988.

${ }^{36}$ Finley, D. B., "Hypersonic Aerodynamics Considerations and Challenges," AIA A Paper 90-5222, Orlando, Fla., 1990.

${ }^{37}$ Cribbs D. W., "Performance Uncertainty Analysis for NASP," AIAA Paper 90-5209, 
Orlando, Fla., 1990.

${ }^{38}$ Feynman, R. P., "What Do You Care What Other People Think?" Further Adventures of a Curious Character Richard P. Feynman, as told to Ralph Leighton, W. W. Norton \& Co., New York, 1988.

${ }^{39}$ Rodney, G. A., "NASA's Post-Challenger Safety Program: Themes and Thrusts," IAF/IAA-88-510, 39th Congress of the International Astronautical Federation, Bangalore, India, Oct. 1988.

${ }^{40}$ Garrick, B. J., "Risk Assessment Practices in Space Industry: The Move Toward Quantification," Risk Analysis, Vol. 9, No. 1, 1989.

${ }^{41}$ Stever, H. G. and Uman, M., "Some Lessons Learned from the Redesign of the Space Shuttle Solid Rocket Booster," AIAA Paper 89-5040, Anaheim, Calif., 1989.

${ }^{42}$ PRA (Probabilistic Risk Assessments) Procedures Guide: A Guide to the Performance of Probabilistic Risk Assessments for Nuclear Power Plants, Vols. 1 \& 2, NUREG/CR-2300, U.S. Office of Nuclear Regulatory Research, Washington, D.C., Jan. 1983.

${ }^{43}$ Adapting Software Development Policies to Modern Technology, Committee on Adapting Software Development Policies to Modern Technology, Air Force Studies Board, National Research Council, National Academic Press, Washington, D.C., 1989.

${ }^{44}$ Hughes, D, "Computer Experts Discuss Merits of Defense Department Software Plan," Aviation Week \& Space Technology, Apr. 16, 1990.

${ }^{45}$ American National Standard Guidelines for the Verification and Validation of Scientific and Engineering Computer Programs for the Nuclear Industry, ANiI/ANS-10.4-1987, American Nuclear Society, La Grange Park, Ill., 1987.

${ }^{46}$ Addenda to Quality Assurance Requirements for Nuclear Facility Applications ASME NQA-2-1989, ASME NQA-2a-1990, American Society of Mechanical Engineers, New York, N.Y., 1990.

${ }^{47}$ Roache, P. J., "Need for Control of Numerical Accuracy," Journal of Spacecraft and Rockets, Vol. 27, No. 2, Mar.-Apr. 1990.

${ }^{48}$ Brown, H., "Compete and Cooperate with Japan," Editorial Section, The Washington Post, Final Edition, Mar. 26, 1990.

${ }^{49} \mathrm{Janis}$, I. L., Groupthink, 2nd Edition, Revised, Houghton Mifflin Company, Boston, 1983.

${ }^{50}$ Harvey, J. B., "The Abilene Paradox: The Management of Agreement," Organizational Dynamics, Vol. 3, No. 1, Summer 1974.

${ }^{51}$ Bell, T. E. and Esch, K., "The Fatal Flaw in Flight 51-L," IEEE Spectrum, Feb. 1987.

${ }^{52}$ Glossary and Tables for Statistical Quality Control, American Society for Quality Control, Milwaukee, Wis., 1983.

${ }^{53}$ Taguchi, G., "Off-Line and On-Line Quality Control Systems," Proceedings of International Conference on Quality Control, Tokyo, Japan, 1978.

${ }^{54}$ Dehnad, K., ed., Quality Control, Robust Design, and the Taguchi Method, Wadsworth \& Brooks/Cole, Advanced Books \& Software, Pacific Grove, Calif., 1989.

${ }^{55}$ Hillis, W. D., "Balancing a Design," IEEE Spectrum, May 1987. 
THE CFD DESIGN TECHNOLOGY DEVELOPMENT TRIAD

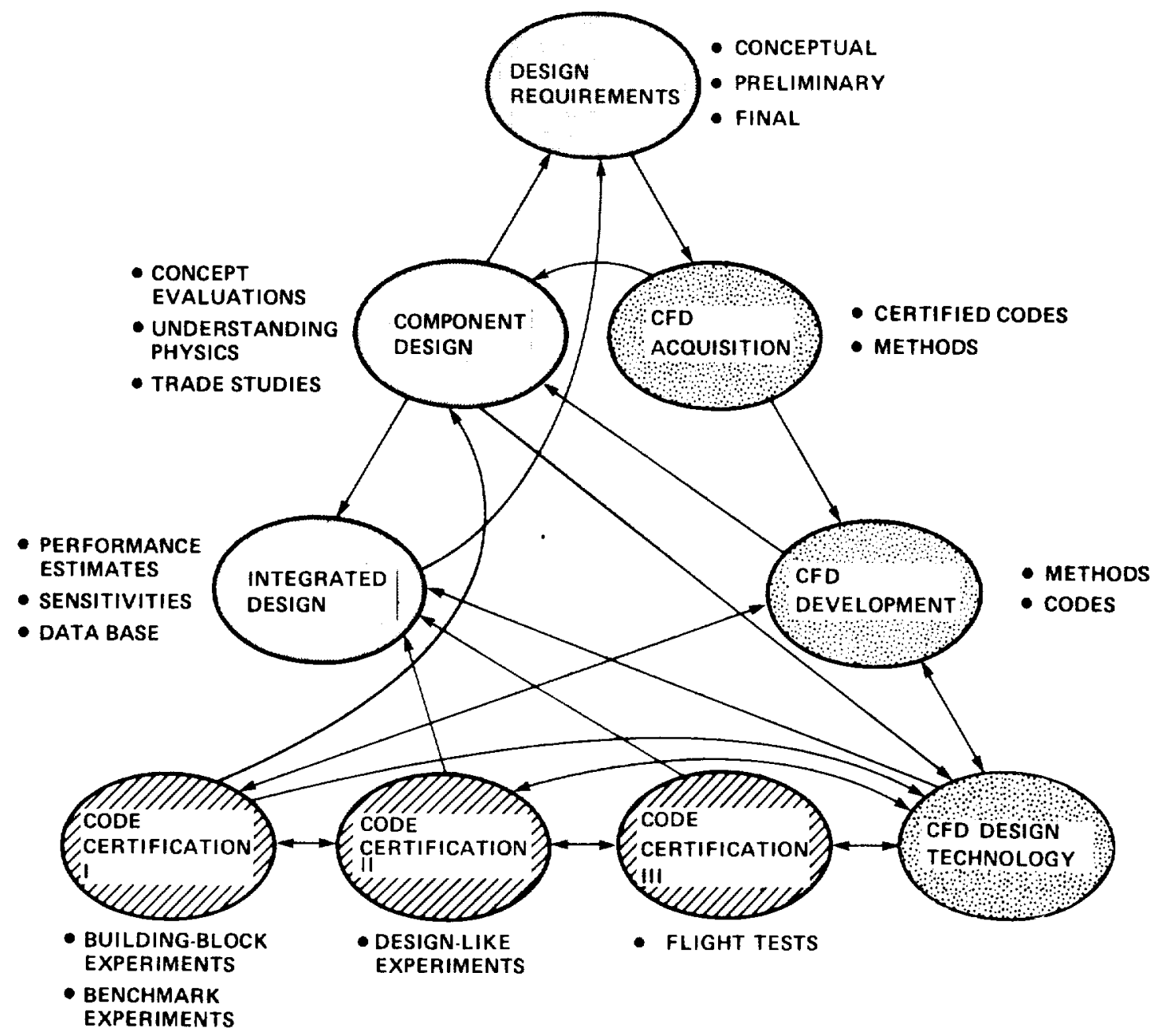

Figure 1: The CFD design technology development triad (from Ref. 14). 

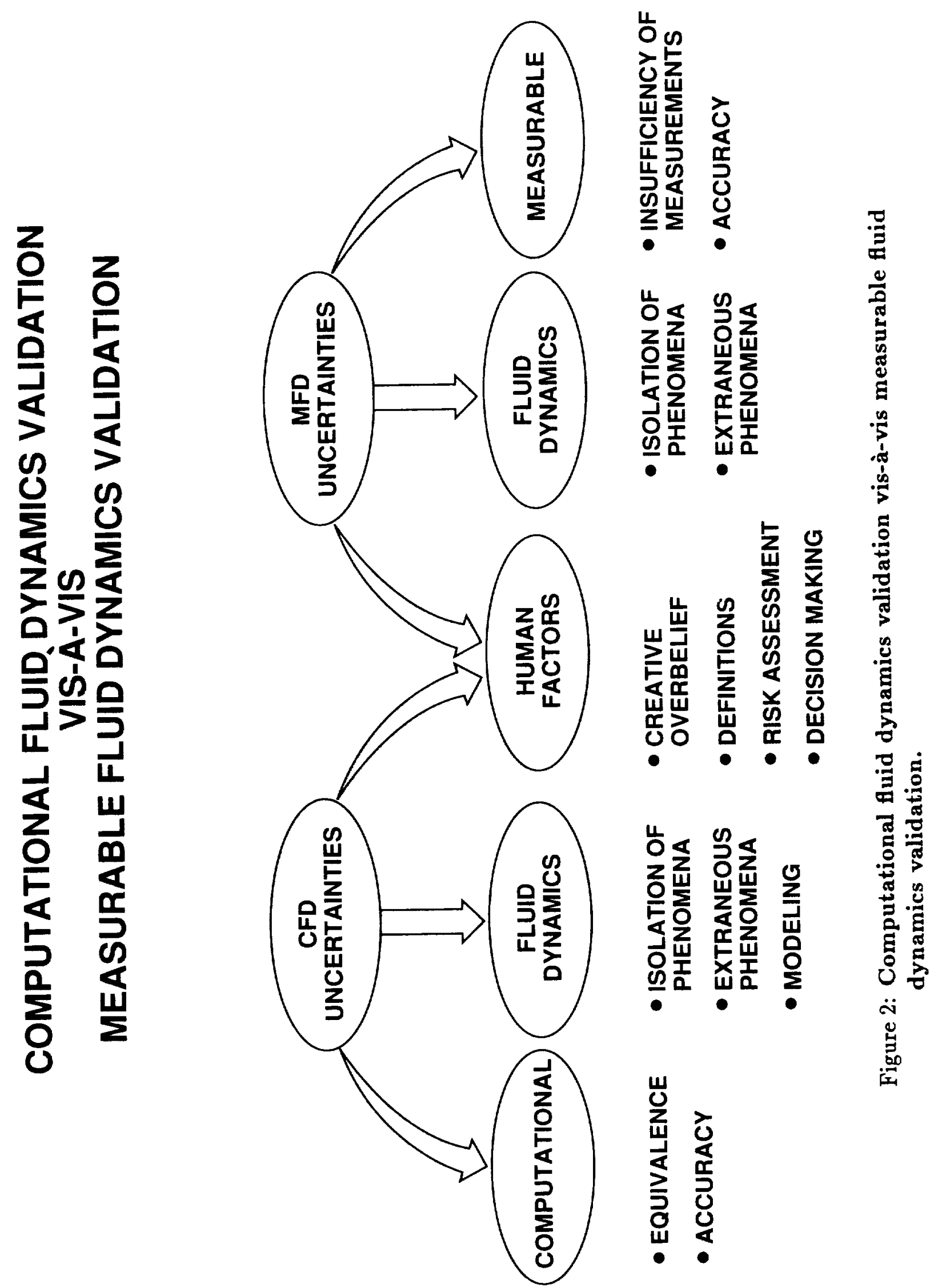


\begin{tabular}{|c|c|c|c|c|}
\hline 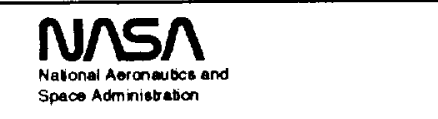 & \multicolumn{4}{|c|}{ Report Documentation Page } \\
\hline $\begin{array}{l}\text { 1. Report No. } \\
\text { NASA TM-102887 }\end{array}$ & \multicolumn{2}{|c|}{ 2. Government Accession No. } & \multicolumn{2}{|c|}{ 3. Recipient's Catalog No } \\
\hline \multirow{2}{*}{\multicolumn{3}{|c|}{$\begin{array}{l}\text { 4. Title and Subtitle } \\
\text { The Aerospace Plane Design Challenge: Credible Computational } \\
\text { Fluid Dynamics Results }\end{array}$}} & \multicolumn{2}{|c|}{$\begin{array}{l}\text { 5. Report Date } \\
\text { December } 1990\end{array}$} \\
\hline & & & \multicolumn{2}{|c|}{ 6. Performing Organization Code } \\
\hline \multirow[t]{2}{*}{$\begin{array}{l}\text { 7. Author(s) } \\
\text { Unmeel B. Mehta }\end{array}$} & & & \multicolumn{2}{|c|}{$\begin{array}{l}\text { 8. Performing Organization Report No. } \\
\text { A-91016 }\end{array}$} \\
\hline & & & \multicolumn{2}{|l|}{$\begin{array}{l}\text { 10. Work Unit No. } \\
505-60\end{array}$} \\
\hline \multicolumn{3}{|c|}{$\begin{array}{l}\text { 9. Performing Organization Name and Address } \\
\text { Ames Research Center } \\
\text { Moffett Field, CA } 94035-1000\end{array}$} & \multicolumn{2}{|c|}{ 11. Contract or Grant No. } \\
\hline \multirow{2}{*}{\multicolumn{3}{|c|}{$\begin{array}{l}\text { 12. Sponsoring Agency Name and Address } \\
\text { National Aeronautics and Space Administration } \\
\text { Washington, DC 20546-0001 }\end{array}$}} & \multicolumn{2}{|c|}{$\begin{array}{l}\text { 13. Type of Report and Period Covered } \\
\text { Technical Memorandum }\end{array}$} \\
\hline & & & \multicolumn{2}{|c|}{\begin{tabular}{|l|} 
14. Sponsoring Agency Code \\
\end{tabular}} \\
\hline \multicolumn{5}{|c|}{$\begin{array}{l}\text { 15. Supplementary Notes } \\
\text { Point of Contact: Unmeel B. Mehta, Ames Research Center, MS 202A-1, Moffett Field, } \\
\qquad \text { CA 94035-1000; (415) 604-5548 or FTS 464-5548 } \\
\text { Presented at the Second AIAA International Aerospace Planes Conference, Orlando, FL, } \\
\text { October 29-31, } 1990 .\end{array}$} \\
\hline \multirow{2}{*}{\multicolumn{5}{|c|}{$\begin{array}{l}\text { Computational fluid dynamics (CFD) is necessary in the design processes of all current } \\
\text { aerospace plane programs. Single-stage-to-orbit (SSTO) aerospace planes with air-breathing supersonic } \\
\text { combustion are going to be largely designed by means of CFD. The challenge of the aerospace plane design } \\
\text { is to provide credible CFD results to work from, to assess the risk associated with the use of those results, } \\
\text { and to certify CFD codes that produce credible results. To establish the credibility of CFD results used in } \\
\text { design, the following topics are discussed: CFD validation vis-à-vis "measurable" fluid dynamics (MFD) } \\
\text { validation; responsibility for credibility; credibility requirement; and a guide for establishing credibility. } \\
\text { Quantification of CFD uncertainties helps to assess success risk and safety risks, and the development of CFD } \\
\text { as a design tool requires code certification. This challenge is managed by "designing" the designers to use } \\
\text { CFD effectively, by ensuring quality control, and by balancing the design process. For designing the } \\
\text { designers, the following topics are discussed: how CFD design technology is developed; the reasons Japanese } \\
\text { companies, by and large, produce goods of higher quality than their U.S. counterparts; teamwork as a new } \\
\text { way of doing business; and how ideas, quality, and teaming can be brought together. Quality control for } \\
\text { reducing the loss imparted to the society begins with the quality of the CFD results used in the design process, } \\
\text { and balancing the design process means using a judicious balance of CFD and MFD. } \\
\text { 17. Key words (Suggested by Author(s)) }\end{array}$}} \\
\hline & & & & \\
\hline \multicolumn{2}{|c|}{$\begin{array}{l}\text { Aerospace plane, Computational fluid dynamics, } \\
\text { Risk assessment, Single-stage-to-orbit, Quantifi- } \\
\text { cation of uncertainties, Sensitivity analysis, } \\
\text { NASP }\end{array}$} & \multicolumn{3}{|c|}{$\begin{array}{l}\text { Unclassified-Unlimited } \\
\text { Subject Category - } 16\end{array}$} \\
\hline $\begin{array}{l}\text { 19. Security Classif. (of this report) } \\
\text { Unclassified }\end{array}$ & $\begin{array}{l}\text { 20. Security Classif. ( } \\
\text { Unclassified }\end{array}$ & age) & $\begin{array}{c}\text { 21. No. of Pages } \\
28\end{array}$ & $\begin{array}{r}\text { 22. Price } \\
\mathrm{A} 03\end{array}$ \\
\hline
\end{tabular}


